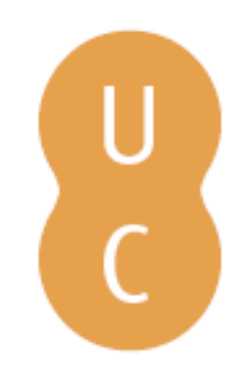

\title{
pompalina
}

\section{Comacchio: água no plural}

$\begin{array}{ll}\text { Autor(es): } & \text { Farinella, Romeo, ed. lit.; Previati, Lucilla; Ronconi, Michele; Dorato, } \\ & \text { Elena; Clementi, Alice; Luciani, Anna; Soltysiuk, Justina }\end{array}$

Publicado por: Imprensa da Universidade de Coimbra

URL

persistente:

URI:http://hdl.handle.net/10316.2/39327

DOI:

DOI:http://dx.doi.org/10.14195/978-989-26-1025-2_12

Accessed : $\quad$ 26-Apr-2023 01:53:49

A navegação consulta e descarregamento dos títulos inseridos nas Bibliotecas Digitais UC Digitalis, UC Pombalina e UC Impactum, pressupõem a aceitação plena e sem reservas dos Termos e Condições de Uso destas Bibliotecas Digitais, disponíveis em https://digitalis.uc.pt/pt-pt/termos.

Conforme exposto nos referidos Termos e Condições de Uso, o descarregamento de títulos de acesso restrito requer uma licença válida de autorização devendo o utilizador aceder ao(s) documento(s) a partir de um endereço de IP da instituição detentora da supramencionada licença.

Ao utilizador é apenas permitido o descarregamento para uso pessoal, pelo que o emprego do(s) título(s) descarregado(s) para outro fim, designadamente comercial, carece de autorização do respetivo autor ou editor da obra.

Na medida em que todas as obras da UC Digitalis se encontram protegidas pelo Código do Direito de Autor e Direitos Conexos e demais legislação aplicável, toda a cópia, parcial ou total, deste documento, nos casos em que é legalmente admitida, deverá conter ou fazer-se acompanhar por este aviso.

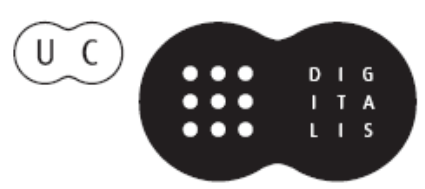




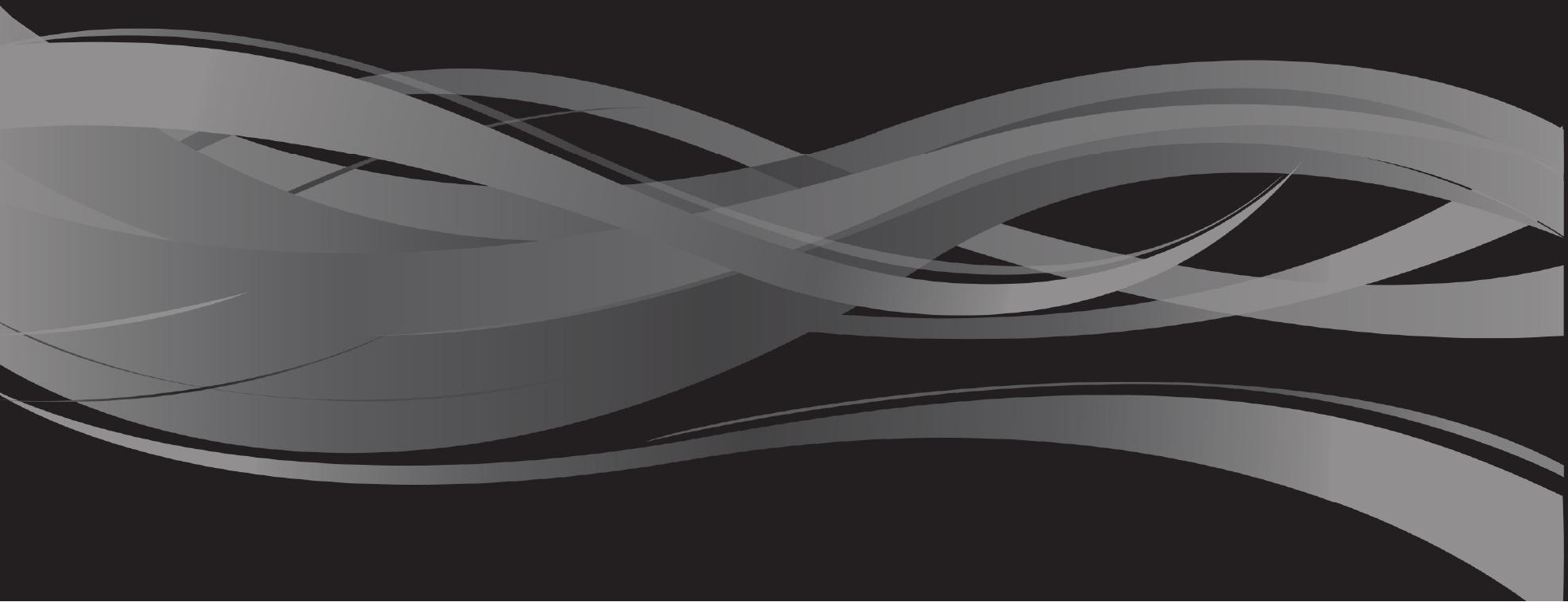


O presente plano diretor pretende resumir e ilustrar um projeto amplo, que permita um imediato e compreensivo olhar sobre toda a área de estudo trabalhada durante o ateliê de projeto do programa europeu "Água como património": este plano funciona, no âmbito do projeto, como aferidor das questões metodológicas definidas pelo grupo de trabalho, inerentes às modalidades de gestão do sistema das águas, em função dos elementos de requalificação do território de Comacchio.

O objetivo que levou a este Programa foi, de facto, o de fornecer um contributo ativo para a redescoberta da importância dos rios e paisagens de água em estratégias de revitalização turística e económica, além da requalificação e valorização urbana e paisagística do território. Esta intenção decorre da extrema riqueza antropológica que estas áreas sempre tiveram na história da civilização humana, tornando esses territórios quase sempre elementos estruturantes que possibilitavam a evolução económica e social das populações aí instaladas.

O âmbito escolhido pelo grupo de trabalho local representou um estudo de caso de extremo interesse, sendo uma paisagem desde sempre configurada e transformada pelos sistemas de controlo, regulamento e aproveitamento das águas. Só a partir do segundo pós-guerra esta simbiose entre artificialização e sistema de águas foi sendo progressivamente reduzida, com efeitos negativos para o atual quadro territorial: poucos recursos hídricos, urbanização descontrolada, depressão económica, inundações, tráfego elevado e degradação.

O passado deixou, no entanto, numerosos testemunhos. Alguns são, atualmente, património histórico e museológico, enquanto outros, ainda "em uso", permitiriam, se adequadamente valorizados, percorrer a génese e as modificações do território em que estão inseridos. O Programa Europeu "Água como património" propõe e estuda um possível cenário: assumir o sistema das águas, um complexo somatório de ambientes e infra-estruturas, em alguns casos sugeridos como hipóteses futuras para desenvolver novamente uma função de estrutura no palimpsesto territorial, de modo a fornecer uma nova estrutura, ordem e renovado valor à paisagem local, contribuindo, ao mesmo tempo, para reduzir ou sanar os problemas supramencionados, que
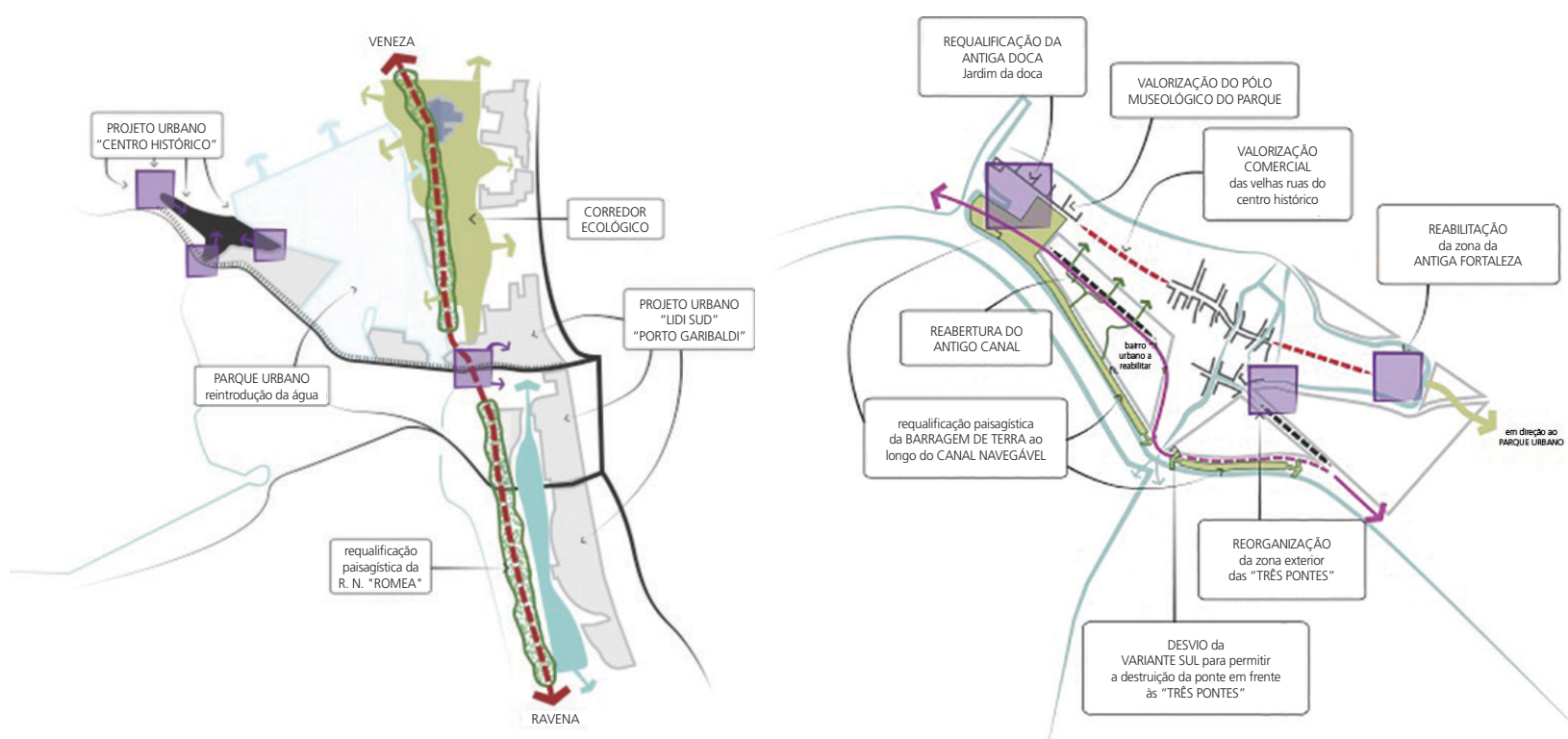



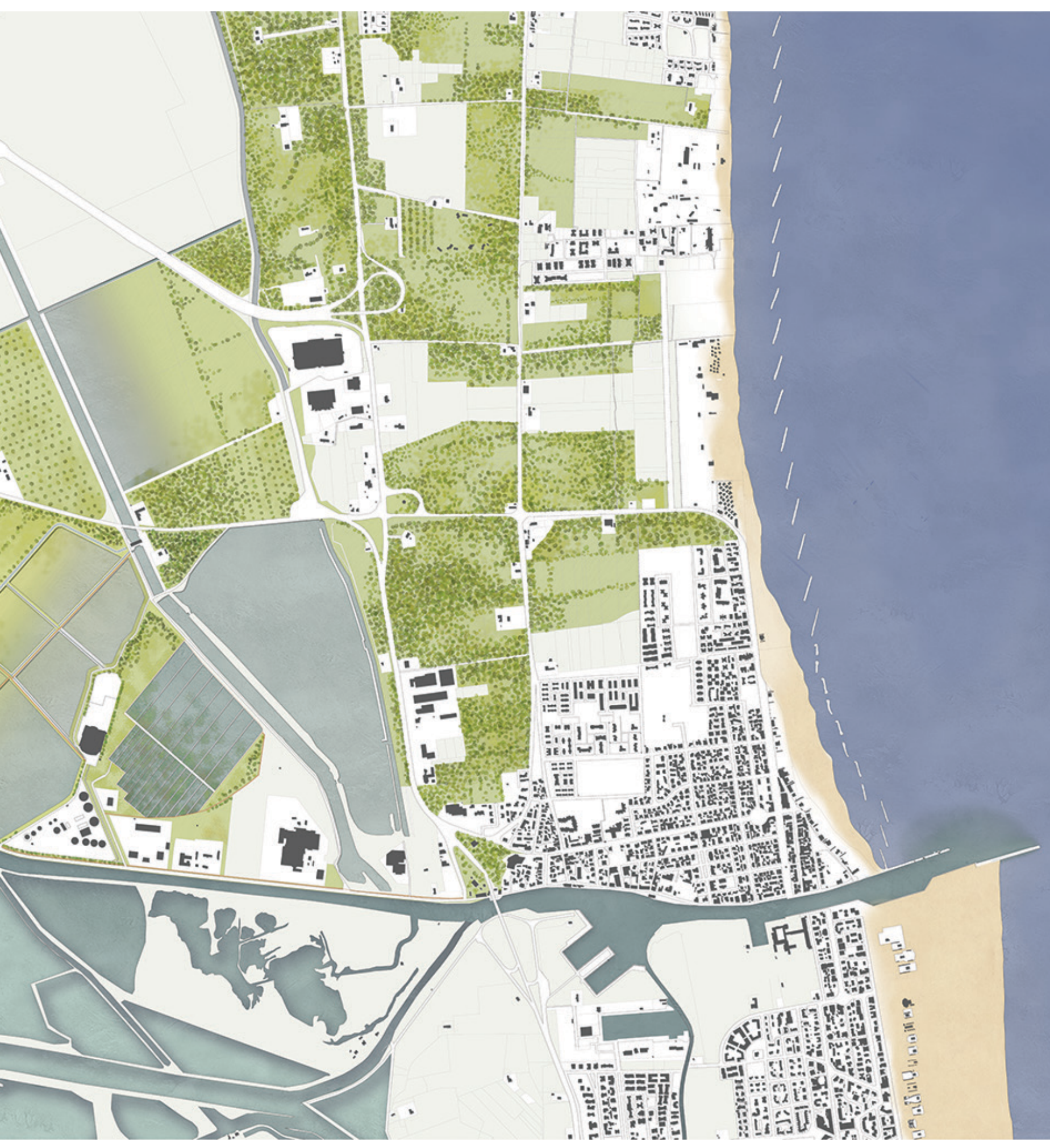


afetam esse contexto. No decurso da fase de projeto deu-se particular atenção à capacidade que os rios e as paisagens de água podem ter de se tornarem espaços públicos, quer no interior dos núcleos urbanizados, quer como elementos de valor ecológico e ambiental quando situados em território rural.

Os êxitos finais do Programa Europeu "Água como património", resumidos no presente texto, pretendem ser um conjunto de "boas práticas" em matéria de planificação urbanística e territorial que, também através de algumas prefigurações de projeto fornecidas como soluções plausíveis para determinadas problemáticas, visam propor uma mudança substancial de direção, em matéria de escolhas de planificação, baseada na necessidade de voltar a partir do elemento fundamental do território local: a água enquanto novo "padrão urbanístico", ou seja, dotada de um grau de obrigatoriedade em cada escolha que comporte uma transformação do território. Uma água capaz de assumir uma pluralidade de funções baseada nas diferentes necessidades: espaço público, infra-estrutura para mobilidade, mecanismo de controlo hídrico, âmbito produtivo, elemento de valor ambiental e componente da paisagem. O Programa Europeu "Água como património" propõe, portanto, o retorno a um uso consciente do sistema das águas como possível alternativa ou contributo para as atuais práticas urbanísticas, as quais demonstraram a incapacidade de poder governar com eficácia e eficiência um território extremamente complexo e contraditório, como é o caso do litoral de Comacchio.

\section{Área ex Eridania}

Propõe-se a requalificação da antiga zona industrial, atualmente desativada e à espera de uma futura reativação, que possa servir as infra-estruturas de transporte de acesso à cidade. Atualmente, é apenas possível chegar a Comacchio através das vias rodoviárias, através de autocarro ou meio de transporte próprio; pelo contrário, propõe-se articular essas modalidades com o apoio, com fins turísticos,

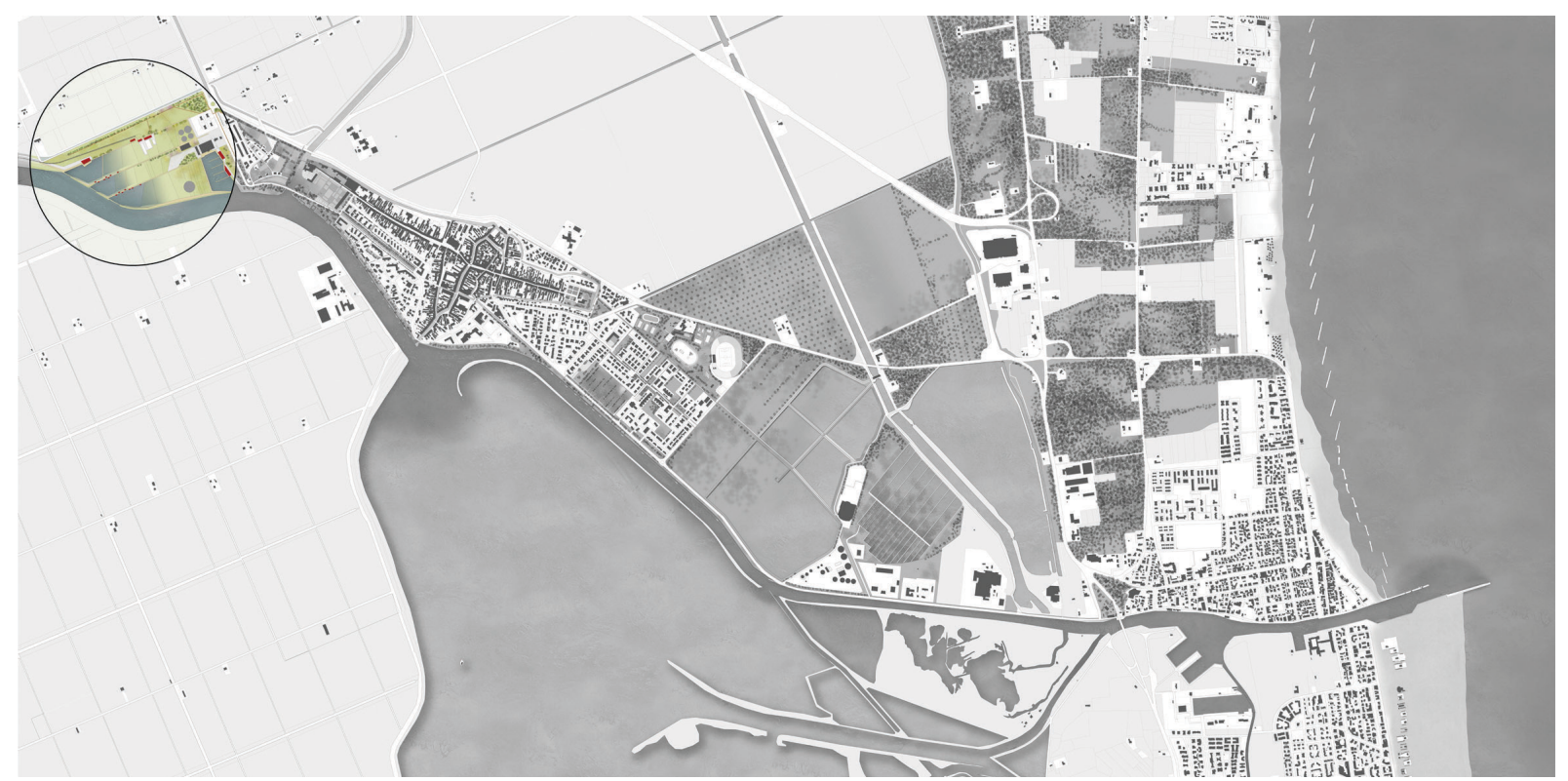


da via fluvial de Ferrara, atualmente objeto de uma importante requalificação, que poderia tornar-se via prioritária de ligação entre o interior, Ferrara e a costa, e através do restabelecimento da linha ferroviária entre Comacchio e Ostellato, destruída durante a segunda guerra mundial. A área da antiga refinaria de açúcar torna-se, na presente proposta, centro dessas renovadas infra-estruturas de ligação, acolhendo os seguintes elementos: estação ferroviária, terminal de autocarros e zona de abastecimento.

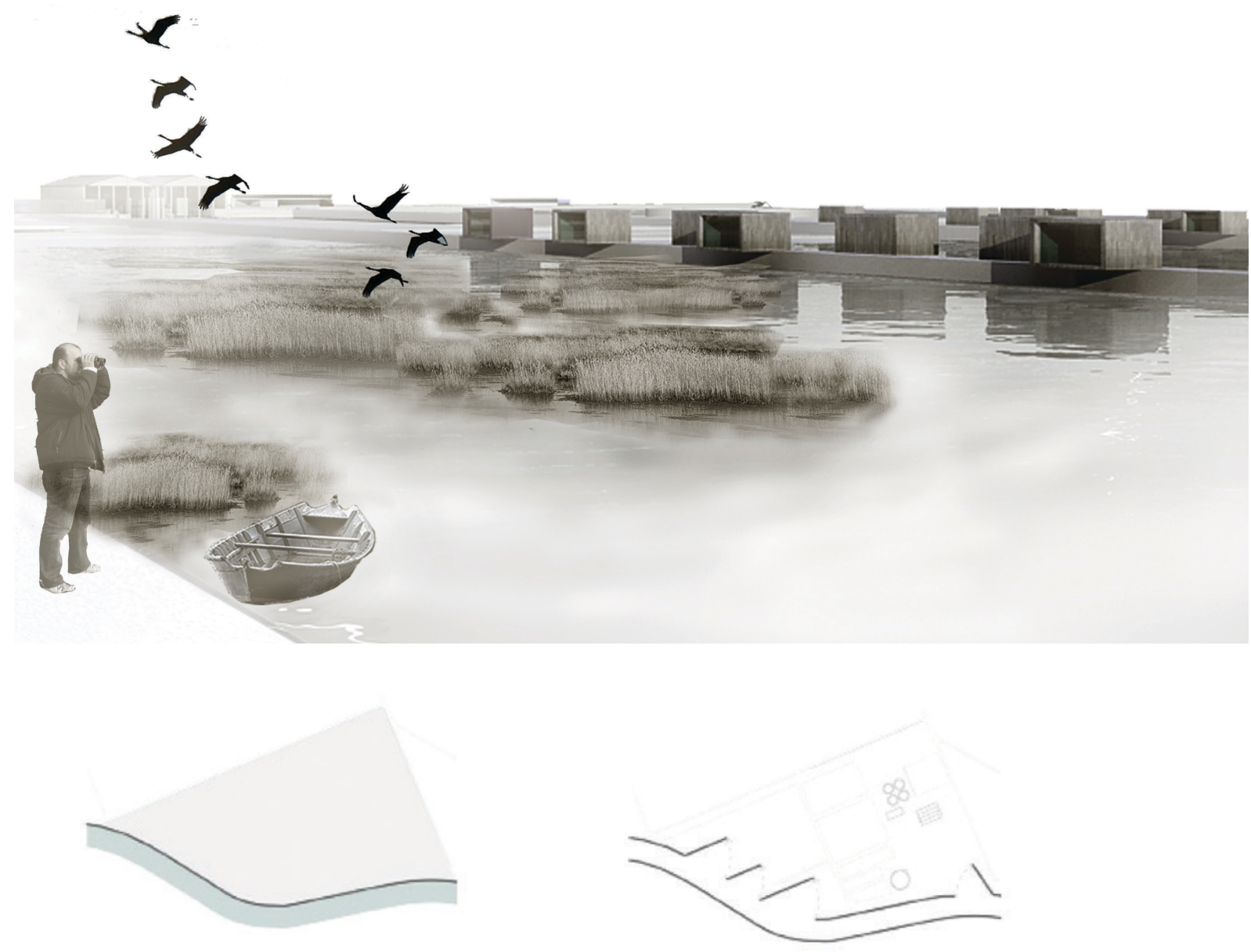

O banco de areia converte-se na interface entre a terra e a água

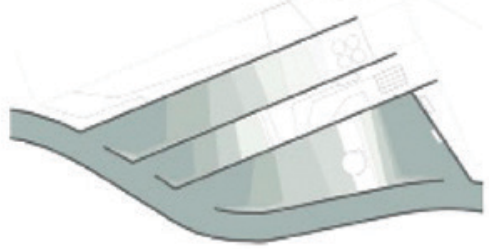

Rasga-se o banco de areia para fazer entrar a água na área intervencionada
Intervem-e nas margens para iniciar uma transformação da paisagem

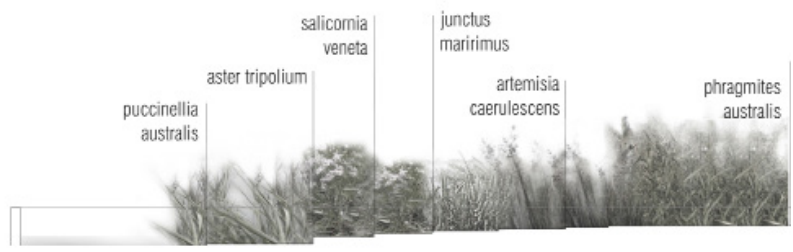

Vegetação espontânea 
Prevê-se também a inclusão dos seguintes serviços: bar, restaurante, hotel e pousada, centro de informações para turistas, aluguer de bicicletas e barcos e serviço de ligação com o centro histórico. O projeto propõe depois uma redefinição das áreas mais relevantes, na margem do Canal Navigabile, com o projeto de percursos pedonais na zona verde, a criação de repositórios para eventuais períodos de menos água e zonas de água para se plantarem essências vegetais hidrófilas, em que seja possível preservar os vestígios arqueológicos do antigo porto de Comacchio, presentes no subsolo.

\section{Villagio San Francesco}

Propõe-se a requalificação dos espaços abertos, existentes no interior e em redor do bairro, atualmente sem uma função definida, em parques públicos e hortos urbanos, de modo a conseguir uma melhor ligação entre o centro histórico e os subúrbios, os quais aparecem hoje como um elemento desassociado do restante núcleo citadino. Nestas novas zonas verdes colocam-se os traçados dos percursos ciclo-pedonais provenientes de Ex Eridania, garantindo uma ligação cómoda e segura com o centro histórico. Graças à redefinição dos espaços abertos, entre o bairro e Comacchio, obtém-se também a reconfiguração da margem ocidental do troço urbano do Canale Marozzo.

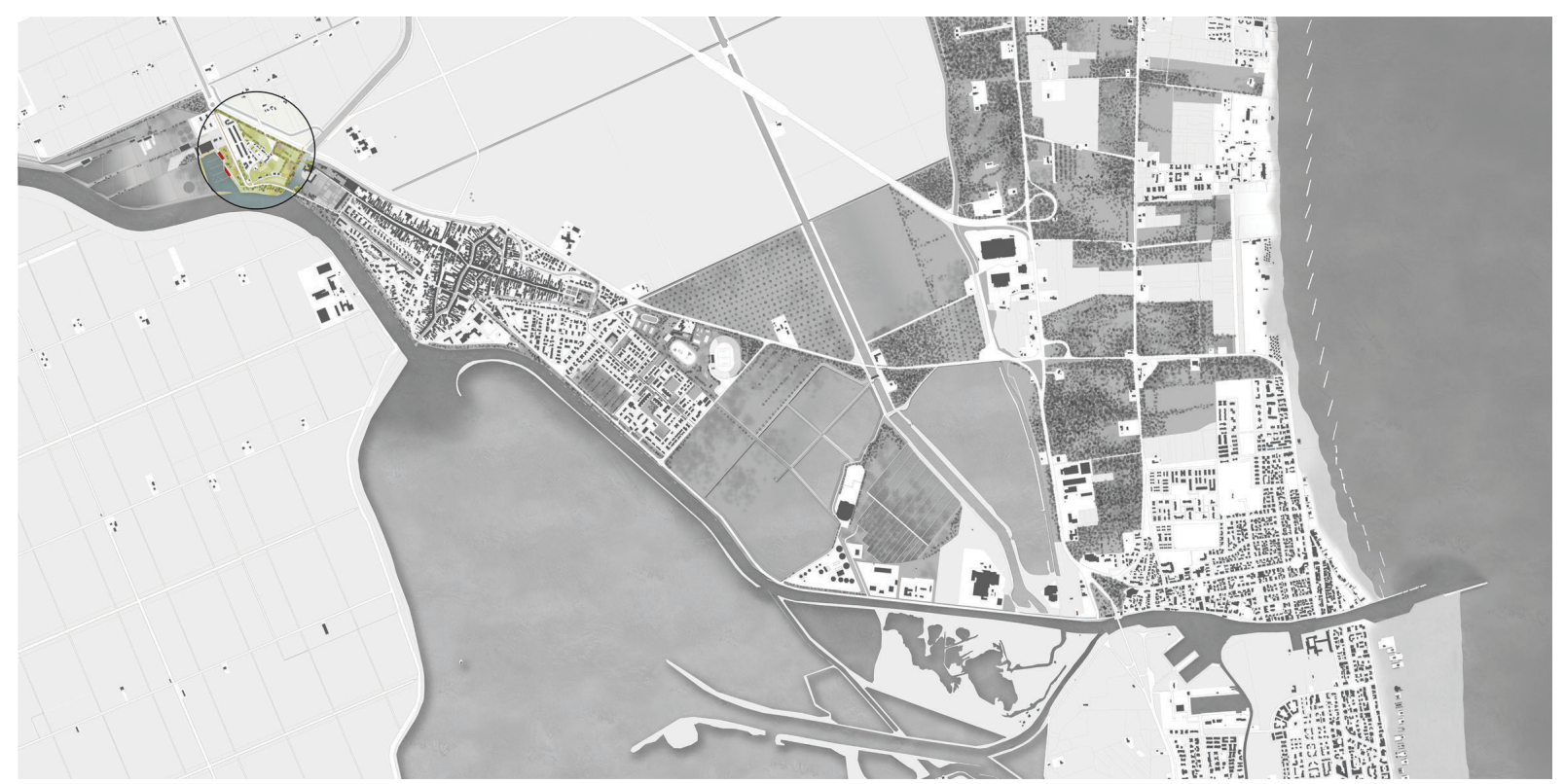

\section{Santa Maria em Aula Regia e o Pórtico dos Capuchinhos}

Propõe-se uma profunda transformação de toda a área, atualmente ocupada por alguns edifícios inutilizados, em parte propriedade pública. Esta situação torna possível a completa demolição, que está 
a ser pensada pela administração municipal, com vista a recuperar a antiga e plena visibilidade, do lado da via Spina, de todo o Pórtico dos Capuchinhos; pretende-se também deslocar mais para Este a via Valle San Carlo, para reabilitar toda a área e acabar com o tráfego rodoviário. O projeto propõe, portanto, transformar toda a área num parque, dotado dos devidos serviços, localizado dentro de uma volumetria em materiais ligeiros, com um prospeto altamente permeável, como uma margem entre o jardim e a cidade; este parque deverá ter amplas superfícies de água, com ligação hidráulica com as vizinhas docas turísticas, de modo a acrescentar valor percetivo ao local. Este novo espaço público poderá ser o palco principal de numerosos acontecimentos que se desenrolam anualmente em Comacchio. Com o objetivo de garantir, neste âmbito, uma vista sobre a via fluvial de Ferrara, coloca-se a hipótese da demolição do único edifício habitacional privado, construído entre a via Spina e o Canale Navigabile, e dos armazéns municipais vizinhos, que se encontram num evidente estado de degradação. O projeto sugere, por fim, a redefinição da vista sobre o canal, através da construção de pequenos espaços em madeira sobre a água.

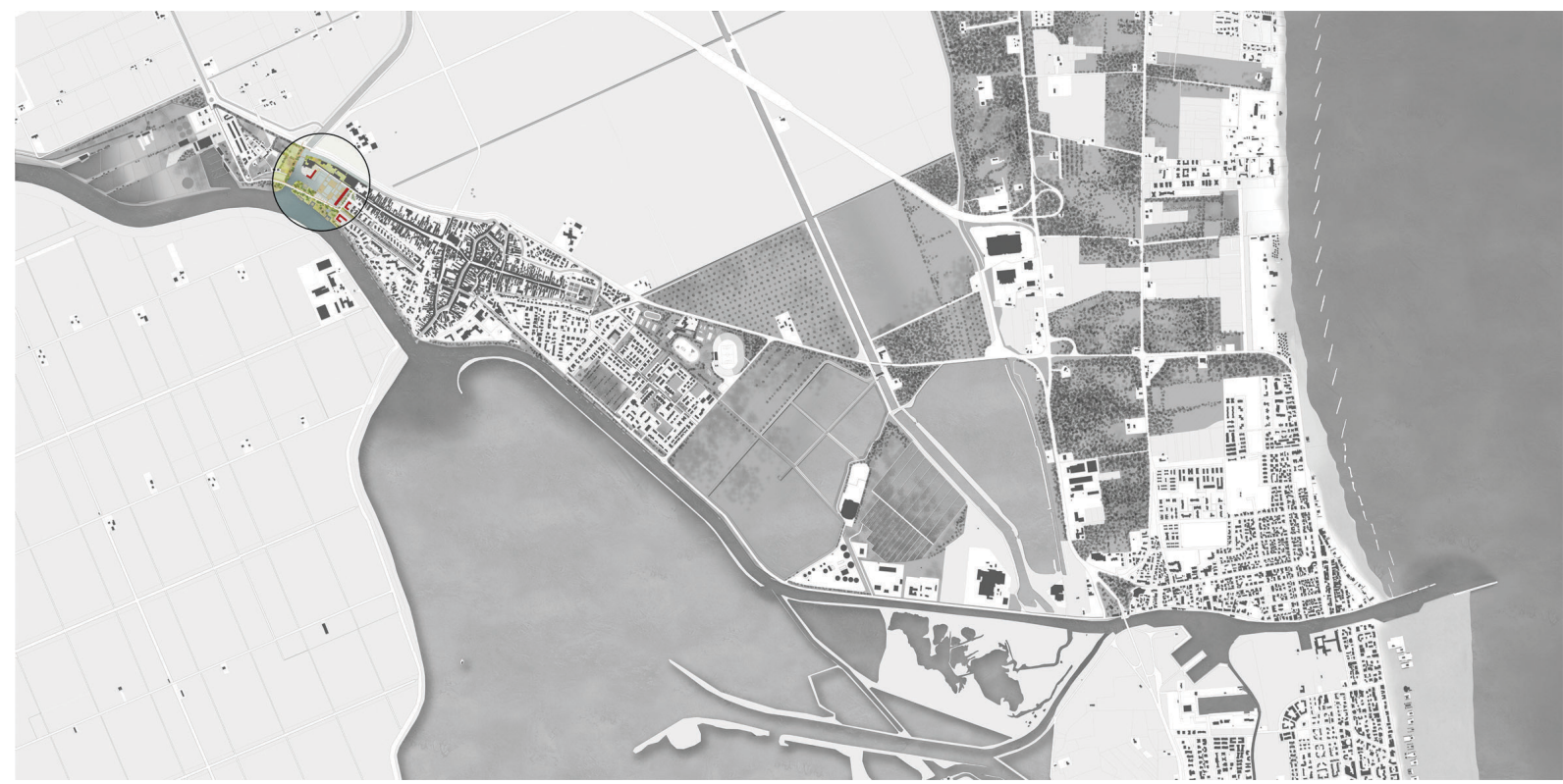

Propõe-se uma redefinição das áreas verdes no lado norte da via Spina, possível graças a uma racionalização dos parques de estacionamento aí existentes e à reabertura do Canale della Francesca, que se desloca atualmente no subsolo. O projeto avança também com algumas intervenções de "cirurgia urbana" no bairro de habitação social a sul da via Spina, com vista à requalificação do espaço verde do centro dos subúrbios, atualmente cercado pelo volume das garagens privadas: propõe-se a recolocação desses anexos, com o objetivo de recuperar o pleno usufruto do jardim público, que poderia assim tornar-se um espaço coletivo para todos os habitantes do bairro.

Serão inseridos também percursos ciclo-pedonais, transversais ao bairro, com ligação a norte com a via Spina e o centro histórico, e a sul com os diques do Canale Navigabile. Em relação a estes diques do canal, atualmente num estado de degradação e ocupado por volumetrias e funções impróprias, 
propõe-se a sua requalificação como espaço público com a inserção de um percurso ciclo-pedonal com pontos de paragem, com a plantação de arvoredos e com a subdivisão em parcelas dos espaços verdes existentes perto dos diques, destinados a hortos urbanos.

A margem do Canale Navigabile torna-se, graças a estas intervenções, um espaço público no cimo dos diques, permitindo a observação privilegiada dos vales vizinhos. Esta é uma estratégia de reaproximação, pelo menos percetiva, entre Comacchio e o seu território. Este percurso dá acesso e termina numa nova pequena praça sobre a água, na parte final da via Agatopisto, por baixo da ponte que atravessa o Canale Lombardo. É um ponto turístico em que se pode usufruir de uma renovada vista sobre os vales.
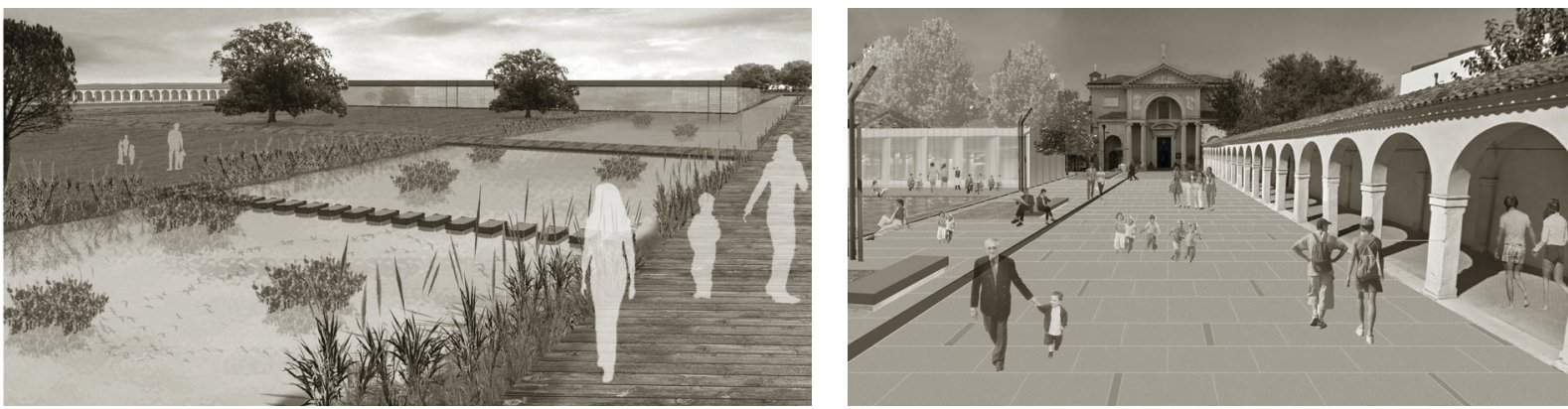

\section{Ex-convento de Sant'Agostino}

O projeto partilha a necessidade, expressa pela administração municipal, de iniciar urgentemente uma intervenção de restauro e requalificação de toda a área, que hoje se encontra num evidente estado de degradação física e estrutural, arriscando comprometer irremediavelmente as

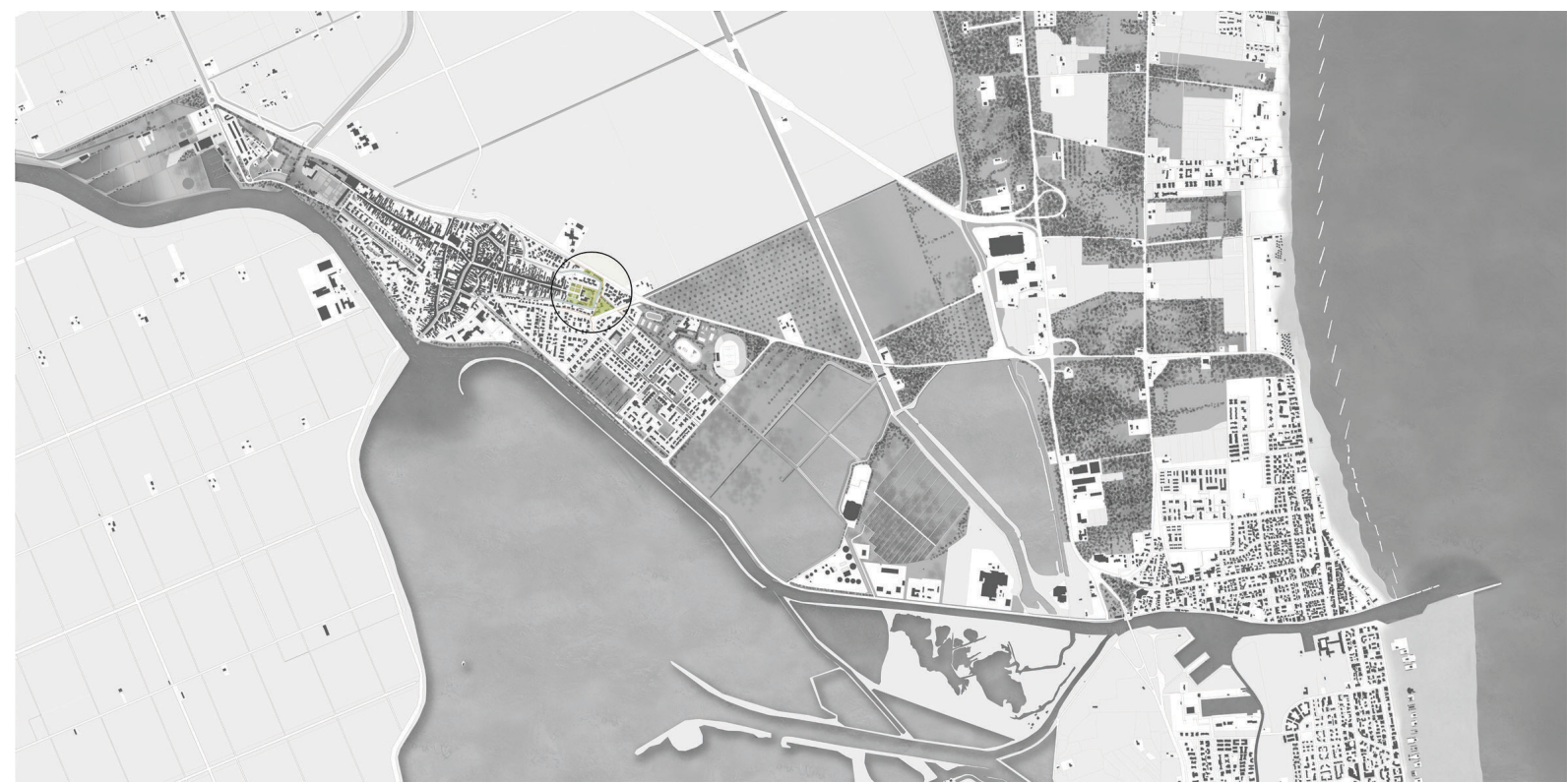


possibilidades de uma eventual recuperação. Propõe-se a redefinição dos espaços verdes adjacentes ao complexo e a inserção de funções públicas e coletivas, que possam dar ao local o estatuto de novo pólo atrativo que possa competir com os fluxos mais concentrados na parte do núcleo histórico, numa estratégia para uma revitalização, também comercial, do Corso Garibaldi. Esta obra torna-se, portanto, um ponto de ligação entre o centro histórico e as áreas periféricas a Este do centro habitacional, garantindo a permeabilidade dos percursos ciclo-pedonais referidos no presente projeto, que vão desde a parte histórica de Comacchio até ao Bairro Raibosola e ao "parque urbano".

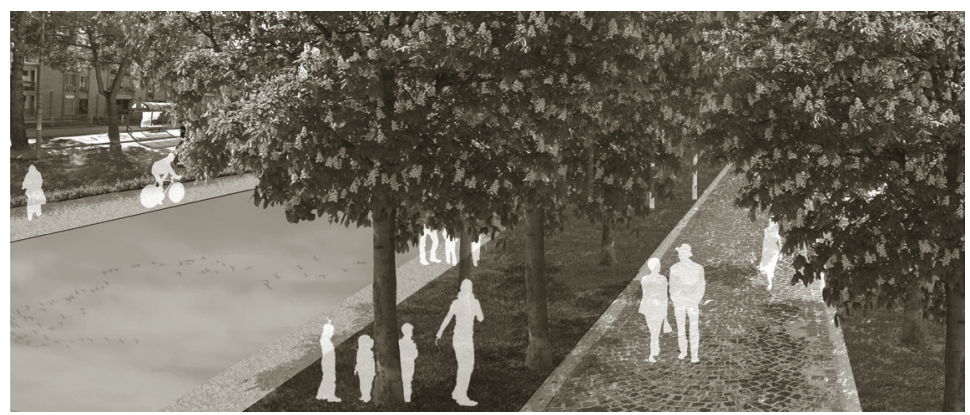

\section{Bairro Raibosola}

No interior do bairro "Raibosola" prevê-se a criação de uma série de percursos ciclo-pedonais, como ligação ao centro histórico e ao "parque urbano". O projeto sugere também a salvaguarda da zona verde na margem da via Marina, com a criação de um jardim público e uma espécie de horto

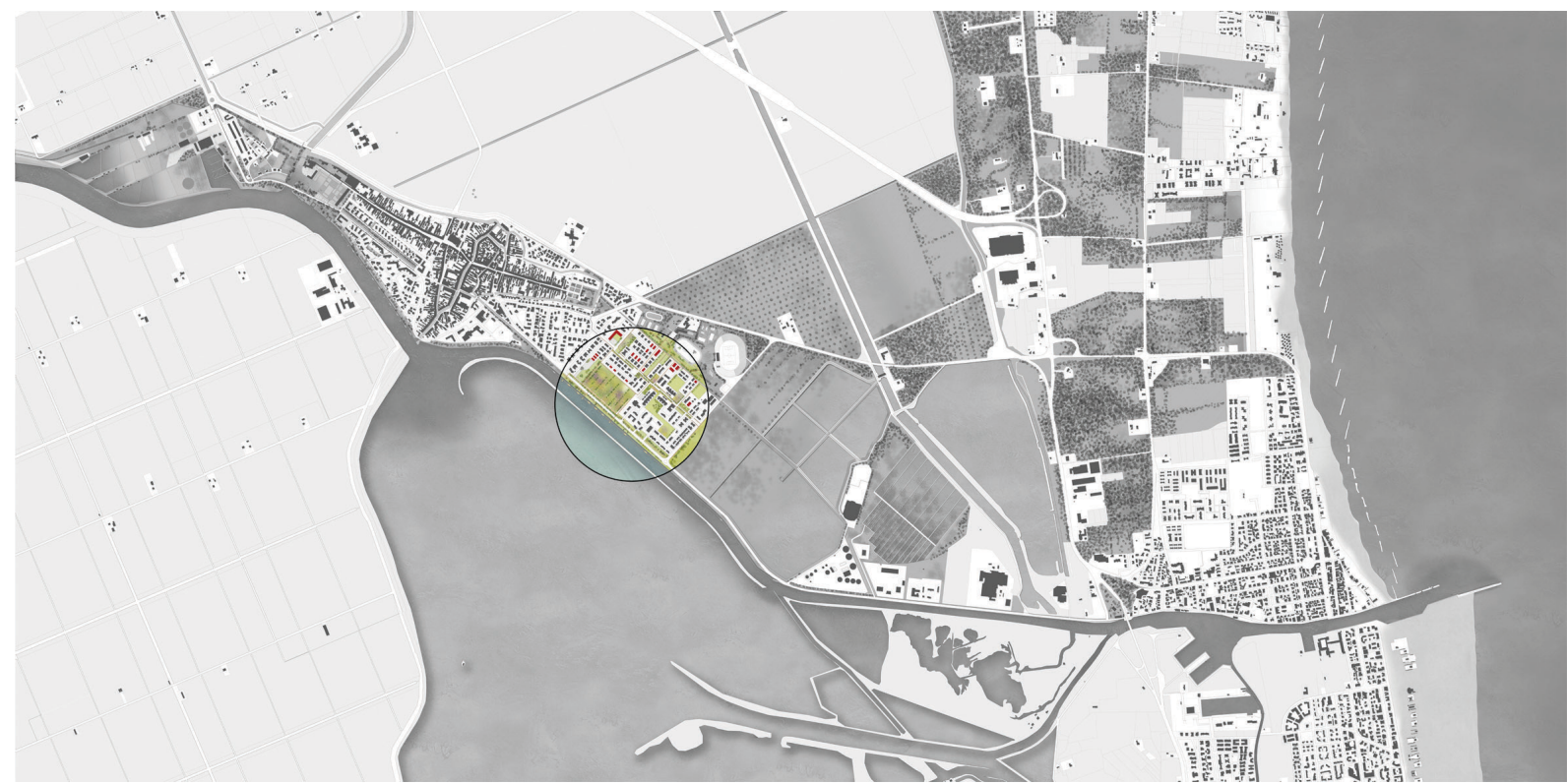


botânico dedicado às essências vegetais que vivem em terrenos com elevada salinidade, como aquelas que já existem no local. Em frente ao bairro propõe-se também a requalificação do dique do Canal Navigabile com a criação de um percurso ciclo-pedonal, dotado de espaços de paragem flutuantes, colocados sobre a via de água.

O projeto reconsidera o carácter das duas estradas paralelas que ligam Raibosola a Este e Oeste:

- a via Marina, que banha o canal a sul, será uma estrada panorâmica de médio tráfego;

- a via Gheraldi, que em direção a Oeste se torna via Pasolo, será fortemente desativada, tornando-se uma estrada quase pedonal e de acesso às residências que não podem ser servidas de outro modo. Será possível, portanto, pôr em relação os espaços abertos presentes em Raibosola.

Haverá mais uma via de comunicação com o centro de Comacchio, reabrindo o canal entre Raibosola e a futura cidade desportiva. O canal será ligado às vias de água que banham o ex-convento de S. Agostino, desempenhando a função de ligação de água entre o bairro, o convento renovado e o resto de Comacchio. Este canal estará também ao serviço da área desportiva aumentando, com os recursos da água, a oferta de atividades.

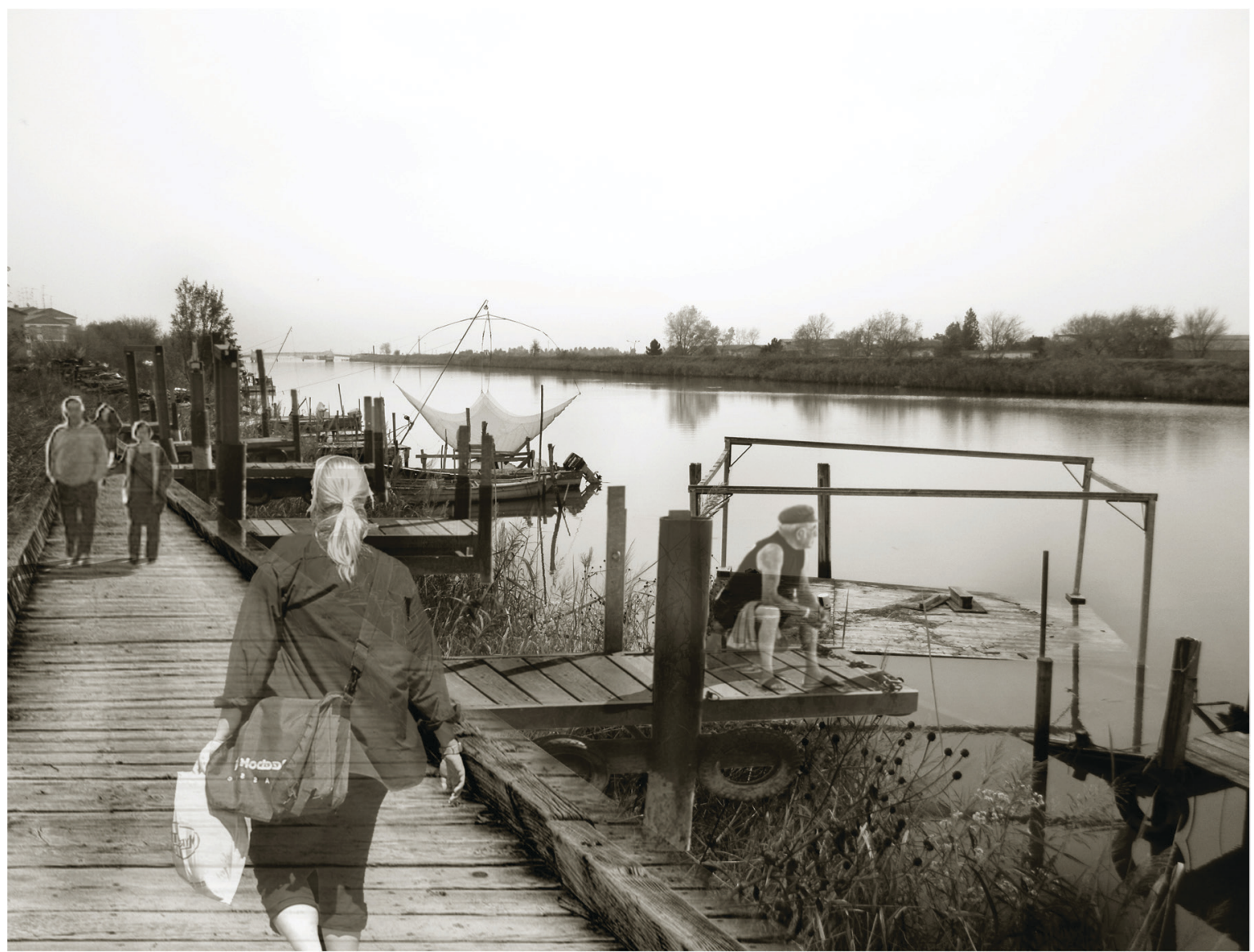




\section{Cidade desportiva}

O projeto prevê a criação, nas áreas a norte do bairro na margem da estrada Provinciale n.15 "Via del Mare", de um vasto centro de atividades desportivas ou de tempo livre para recolocar algumas funções atualmente localizadas junto ao nó monumental de Santa Maria em Aula Regia. O presente projeto incluiu a transferência desta área para a cidade desportiva para se integrar com outras instalações, como por exemplo uma piscina municipal que atualmente não existe em Comacchio. A administração municipal está também envolvida no projeto. Esta solução é também uma hipótese para uma integração num centro multiusos do estádio da cidade, que hoje está afastado do centro urbano. Na presente proposta, esta cidade desportiva será também uma zona de segurança, situada entre o bairro e o eixo da estrada Provinciale, também graças à criação de um arvoredo na margem da artéria.

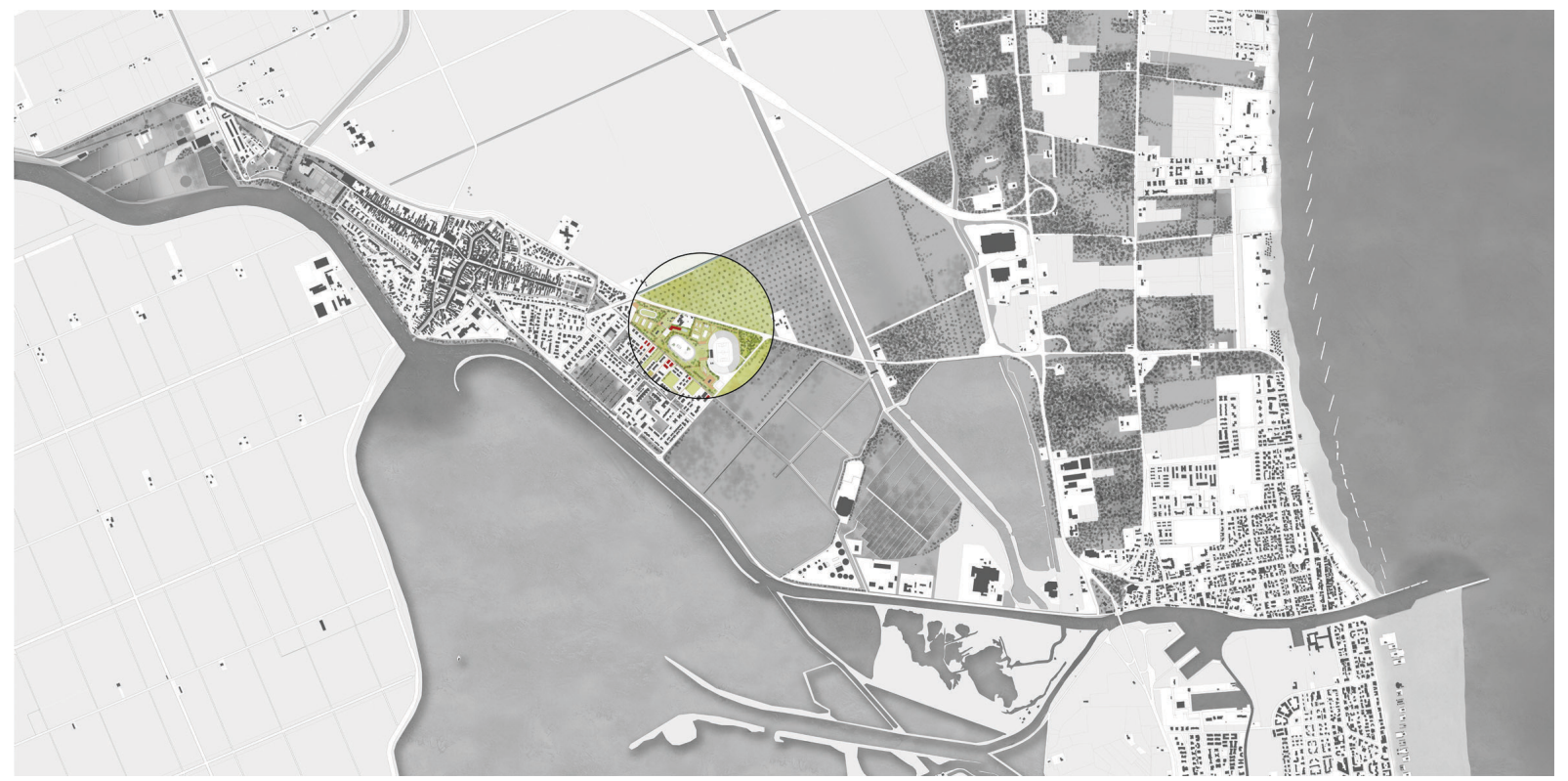

\section{Parque urbano}

Dentro deste vasto âmbito periurbano, atualmente subutilizado em termos agrícolas devido ao pouco rendimento dos terrenos, o projeto propõe a criação de um "parque periurbano" com arvoredo, percursos e equipamentos para o tempo livre, espaços verdes perto do edifício construído e zonas alagáveis para os períodos de maior seca da rede hidrográfica. Confirmam-se as previsões de aumento da área cemiterial, para a qual se propõe uma mitigação com a criação de um arvoredo. Prevê-se também a criação de uma série de reservatórios para fitodepuração, em ligação com o depurador comunal, atualmente objeto de um projeto para a sua atualização técnica. 

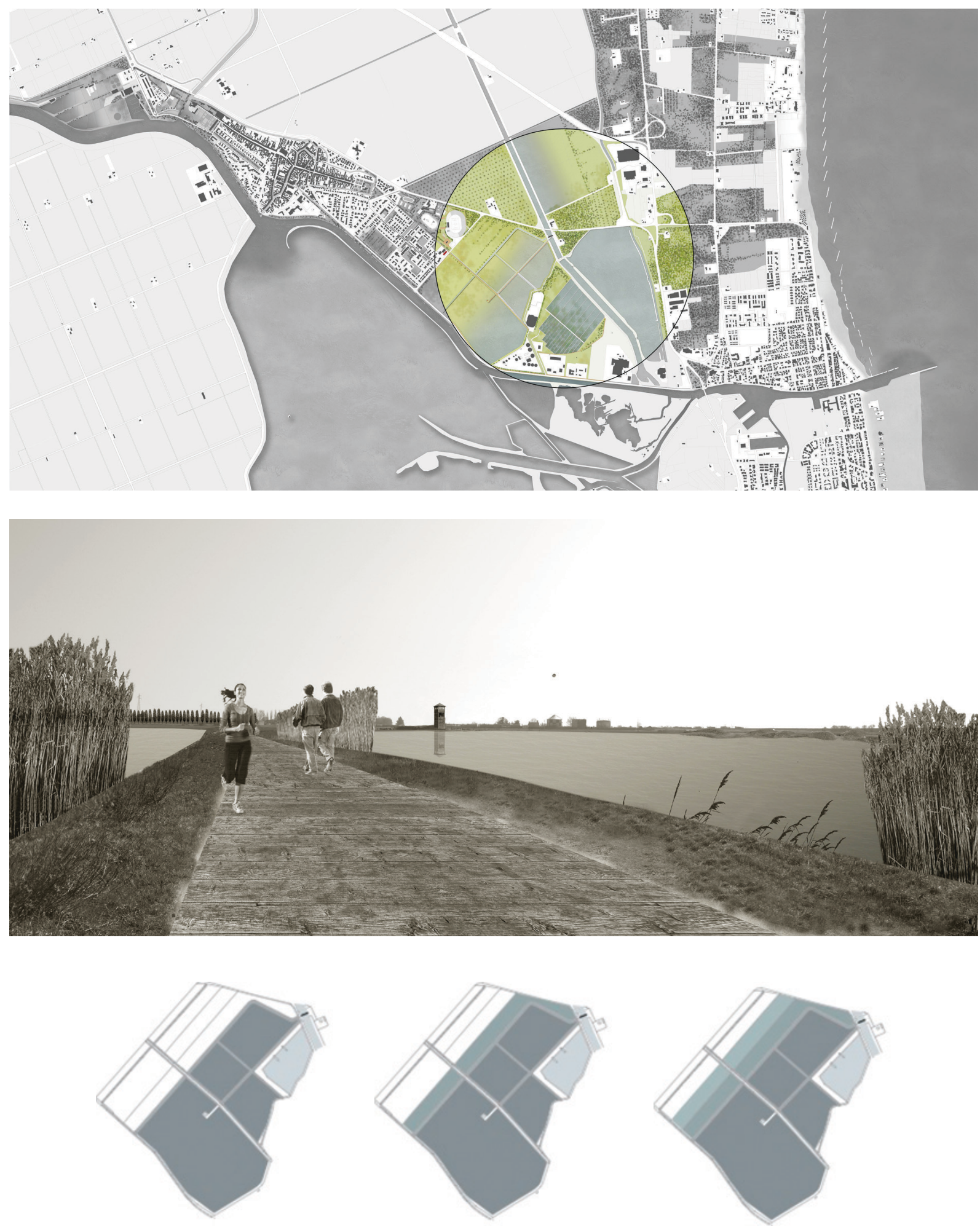

Alagamento progressivo e controlado 